\title{
Design of Polar-Fuzzy-Controller to Impair Current Harmonics in Power System
}

\author{
Harsha Vanjani $^{\# 1}$, Meha Sharma ${ }^{* 2}$, U. K. Choudhry ${ }^{\# 3}$ \\ ${ }^{\# 1}$ Research Scholar, EEE - ECE Department, Ansal University, Gurgaon, India \\ ${ }^{1}$ harshavanjani@gmail.com
}

\begin{abstract}
The aim of the paper is to design a new Fuzzy Logic Controller to control Three-phase Shunt Active Power Filter for achieving the upgraded operation of power system under nonlinearity.

Methodology - The Polar fuzzy logic based Controller is implemented with only one input and one output. As it has less number of rules and membership function compared to conventional type of fuzzy logic controller. This Polar Fuzzy Logic Controller has given polar co-ordinate of dc link voltage as input.

Findings -The simulation result show that the proposed method settle down dc link voltage better than Proportional Plus Integral controller and it reduces the Total Harmonic Distortion factor effectively. The estimated operation time of the system is reduced through Polar Fuzzy Logic Controller which is designed with two fuzzy rules. The stability and performance of the power systems are improved.
\end{abstract}

Originality-A Polar co-ordinate based controller with minimum estimated operational time is developed, which is capable to meet requirements of IEEE standard-519.

Keyword - Keyword1, Active Power Filter, Estimated Time, Harmonics, Polar Fuzzy Logic Controller, Power System

\section{INTRODUCTION}

Recently the usage of power electronics components and devices based on it has been increased tremendously, which is producing many power quality problems. These non-linear loads are responsible to draw reactive power, neutral current and odd harmonics in large quantities. These odd harmonics are responsible for poor power factor, equipment overheating, random circuit breaker tripping etc. They cause interference in communication networks. Thus, overall efficiency of the system decreases.

To make the efficient system, passive filters were used to mitigate harmonics previously. They have drawbacks like resonance, fixed compensation and large size. Thus, they do not meet the recent demand of the modern commercially used equipment's. Active Power Filters (APF) have been developed and fulfilled the desire of the industry. Shunt Active Power Filter (SAPF) solves harmonic related problems of power quality such as inter harmonics, subharmonics, reactive current, unbalanced current produced by nonlinear load. SAPF can accommodate Current Source Inverter (CSI) or Voltage Source Inverter (VSI). VSI has Pulse Width Modulation (PWM) and it is adopted globally over to develop SAPF because of low cost, reduced size, light weight and reduced losses [1]-[2].

Various control techniques have been implemented to generate compensating currents. Most common controller used to control APF is Proportional Plus Integral (PI) controller which removes steady state error [3][5]. This conventional technique stands in need of mathematical models. These models are incapable to reach requirements with parameter variation and load disturbances.

Fuzzy Logic Controller (FLC) does not require any mathematical model, can do excellent job with estimated inputs. The functioning of FLC (consisting of three functions: fuzzification, approximate reasoning and defuzzification blocks) depends on number of rules, knowledge base, number of membership function, shape of membership function and overlapping of it. The number of fuzzy membership function decides estimated time, memory requirement and complexity of the system. Most of the research has been done on Traditional FLC. Though Traditional FLC gives better performance compared with the PI controller [6]-[7] in transient condition in terms of overshoot, but it has large number of rules. Generally, 49 rules are used to design Traditional FLC to control SAPF [8]-[16]. These rules make the system complex and require large time. To overcome these problems Polar Fuzzy Logic Controller (PFLC) with rotational characteristics has been introduced in this paper. This concept was derived in 1990 [17]. PFLC proposed a strategy in which the number of membership function can be reduced significantly. In this paper, PFLC has been implemented for a three-phase SAPF to achieve current harmonics as per the IEEE std-519 [18]. The results of PFLC are compared with PI controller to check the robustness of the controller. 


\section{Formulation OF REFERENCE SOURCE CURRENT}

SAPF works on compensation principle. Either it has to supply a compensating current to the system or it has to draw a compensating current from the system to impair harmonics, reactive power balancing and to bring supply current in phase with supply voltage.

Figure 1 shows working of SAPF as compensator. Applying Kirchhoff's law at Point of Common Coupling, Source current in terms of compensating current given by SAPF can be written as,

$$
\boldsymbol{i}_{\boldsymbol{a}}(\boldsymbol{t})=\boldsymbol{i}_{b}(t)-\boldsymbol{i}_{c}(t)
$$

Source current is denoted by $\mathrm{i}_{\mathrm{a}}(\mathrm{t})$, load current is denoted as $\mathrm{i}_{\mathrm{b}}(\mathrm{t})$ and $\mathrm{i}_{\mathrm{c}}(\mathrm{t})$ is compensating current generated by SAPF. So, compensating current is written as

$$
i_{c}(t)=i_{b}(t)-i_{a}(t)
$$

The productivity of the controller is on calculation of reference current.

$$
i_{a}(t)=i_{m} \sin (w t),
$$

By controlling the dc link voltage $\mathrm{i}_{\mathrm{m}}$ can be calculated. The Clarke transformation is used to achieve the results.

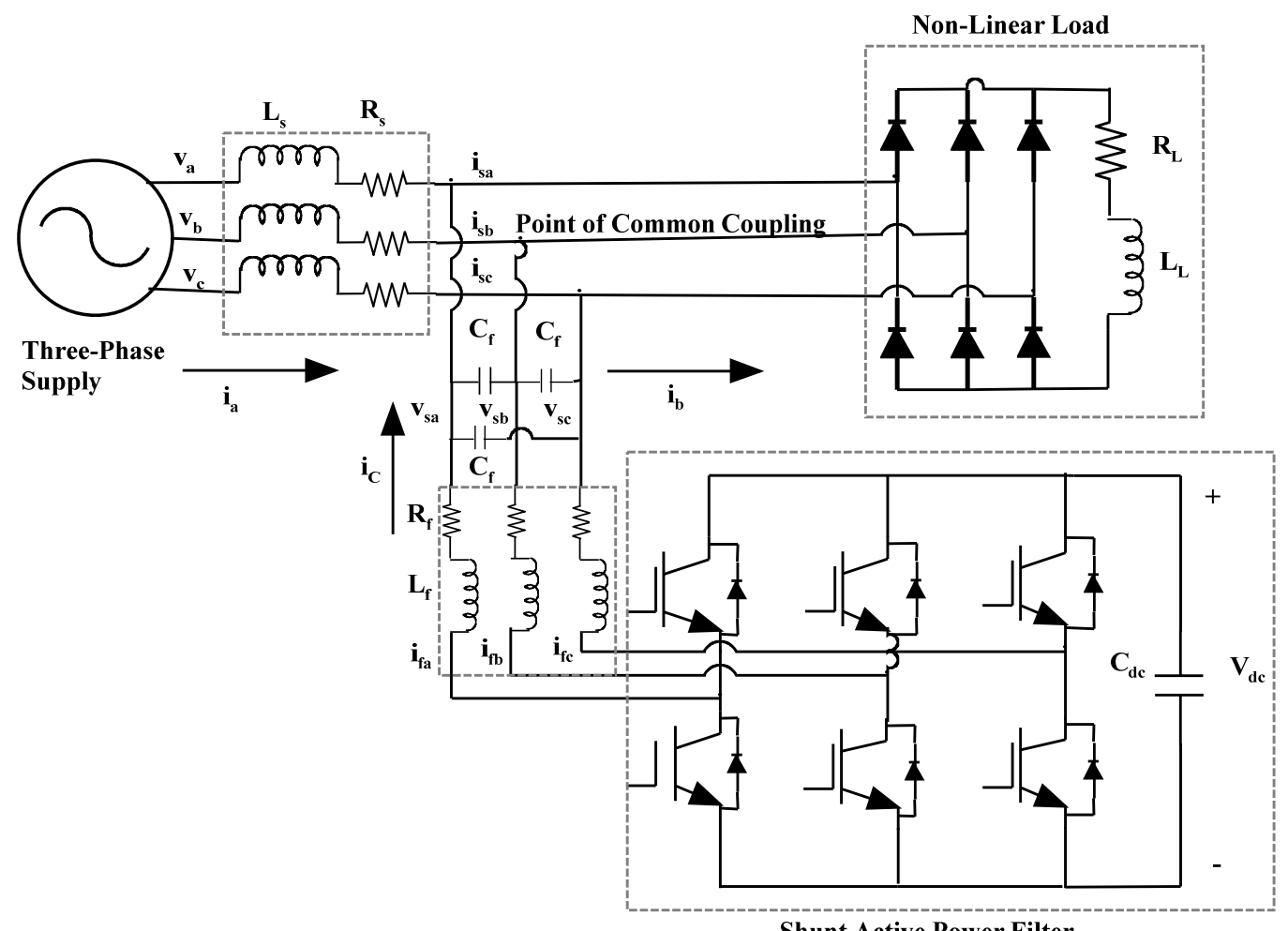

Shunt Active Power Filter

Fig. 1. SAPF as Compensator

In the Clarke Transformation, three-phase load voltages $\mathrm{V}_{\mathrm{sa}}, \mathrm{V}_{\mathrm{sb}}, \mathrm{V}_{\mathrm{sc}}$ and load currents $\mathrm{I}_{\mathrm{la}}, \mathrm{I}_{\mathrm{lb}}, \mathrm{I}_{\mathrm{lc}}$ is used to generate active power pand reactive powerq according to following equations.

$$
\begin{aligned}
& {\left[\begin{array}{l}
V_{\alpha} \\
V_{\beta}
\end{array}\right]=\sqrt{\frac{2}{3}}\left[\begin{array}{ccc}
1 & -1 / 2 & -1 / 2 \\
0 & \sqrt{3} / 2 & -\sqrt{3} / 2
\end{array}\right]\left[\begin{array}{l}
V_{s a} \\
V_{s b} \\
V_{s c}
\end{array}\right]} \\
& {\left[\begin{array}{l}
i_{\alpha} \\
i_{\beta}
\end{array}\right]=\sqrt{\frac{2}{3}}\left[\begin{array}{ccc}
1 & -1 / 2 & -1 / 2 \\
0 & \sqrt{3} / 2 & -\sqrt{3} / 2
\end{array}\right]\left[\begin{array}{l}
i_{L a} \\
i_{L b} \\
i_{L c}
\end{array}\right]} \\
& {\left[\begin{array}{l}
p \\
q
\end{array}\right]=\left[\begin{array}{ll}
V_{\alpha} & V_{\beta} \\
V_{\beta}-V_{\alpha}
\end{array}\right]\left[\begin{array}{l}
i_{L \alpha} \\
i_{L \beta}
\end{array}\right]}
\end{aligned}
$$



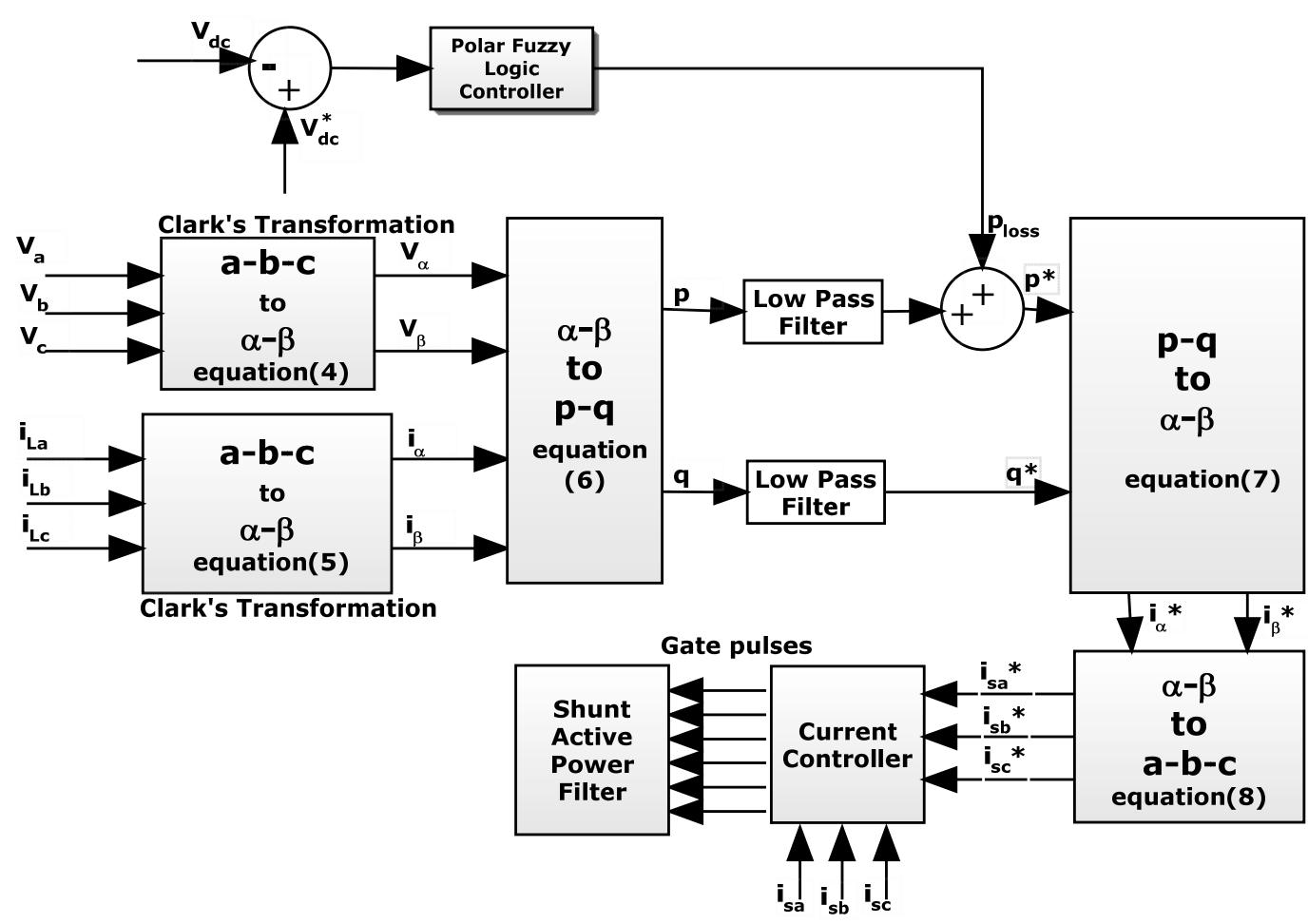

Fig. 2. Block Diagram of IRP theory

Instantaneous Reactive Power (IRP) theory is explained in Fig. 2 (19). A Low Pass Filter is used to separate dc component from $\mathrm{p}$ and $\mathrm{q}$. The total active power loss (switching and conduction loss) in the compensation process is referred asp $\mathrm{p}_{\text {loss }}$. The reference currents $\mathrm{i}_{\mathrm{sa}}^{*}, \mathrm{i}_{\mathrm{sb}}^{*}, \mathrm{i}_{\mathrm{sc}}^{*}$ is calculated using $\mathrm{p}^{*}$ and $\mathrm{q}^{*}$ from following equations.

$$
\begin{aligned}
& {\left[\begin{array}{l}
i_{\alpha} \\
i_{\beta}
\end{array}\right]=\frac{1}{V_{\alpha}^{2}+V_{\beta}^{2}}\left[\begin{array}{cc}
V_{\alpha} & V_{\beta} \\
V_{\beta} & -V_{\alpha}
\end{array}\right]\left[\begin{array}{l}
p^{*} \\
q^{*}
\end{array}\right]} \\
& {\left[\begin{array}{l}
i_{s a}^{*} \\
i_{s b}^{*} \\
i_{s c}^{*}
\end{array}\right]=\sqrt{\frac{2}{3}}\left[\begin{array}{rrr}
1 & -\frac{1}{2} & -\frac{1}{2} \\
0 & \frac{\sqrt{3}}{2} & -\frac{\sqrt{3}}{2}
\end{array}\right]\left[\begin{array}{cc}
V_{\alpha} V_{\beta} \\
-V_{\beta} V_{\alpha}
\end{array}\right]^{-1}\left[\begin{array}{l}
p^{*} \\
q^{*}
\end{array}\right]}
\end{aligned}
$$

These currents are compared with actual source currents to generate gate pulses for the PWM VSI. In this model, Insulated Gate Bipolar Transistors (IGBT) is used as switching device for VSI. The pulses of gate which is given to the IGBTs are generated via current controller. The accuracy of the reference current depends on functioning of controller.

\section{III.Proposed Polar Fuzzy Logic ConTroller}

In the PFLC technique, fuzzy sets are represented by polar co-ordinates. The Real (x) and Imaginary (y) part of the cartesian co-ordinates can be represented into polar co-ordinates, magnitude (R) and angle $(\theta)$ as shown in Fig. 3. The execution of the PFLC essentially depends on angle $\theta$. Fuzzy sets of PFLC can be illustrated in universe of circle therefore repeats shape in every $360^{\circ}$. 


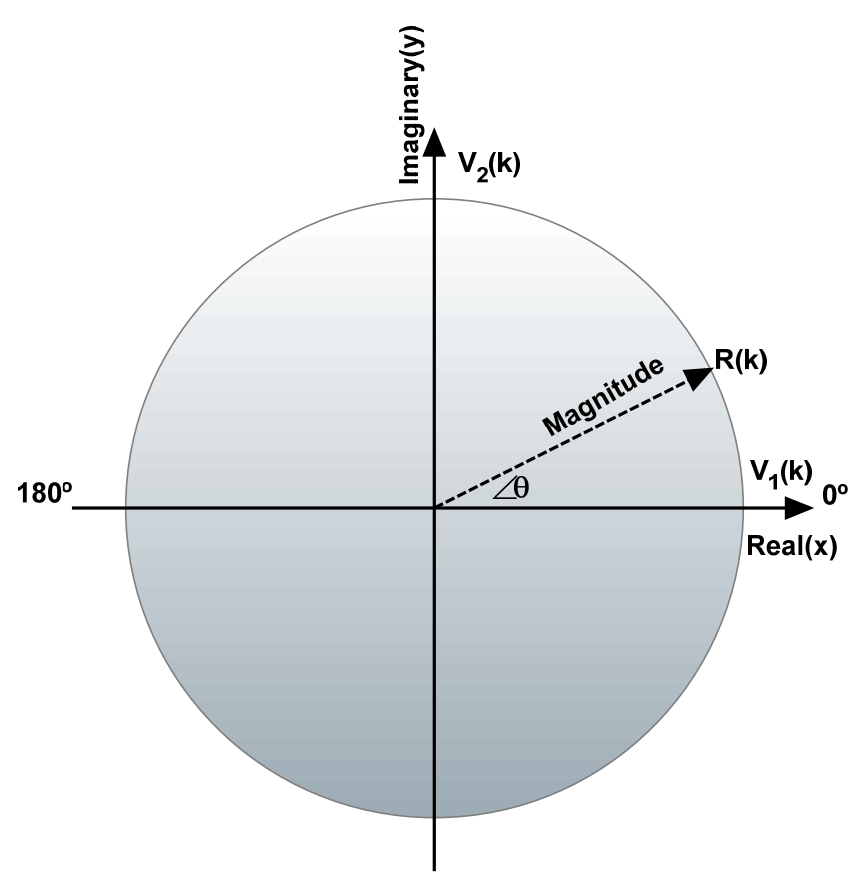

Fig. 3. Polar Phase Plane

Conventional fuzzy logic techniques are based on two inputs, change in voltage $v_{1}=\Delta v$ and derivative of change in voltage $\mathrm{v}_{2}=\frac{\mathrm{dv}}{\mathrm{dt}}$ but in PFLC only one input angle $(\theta)$ is given thus number of rules decreases instantly (20). Here, $v_{1}$ and $v_{2}$ are the real and imaginary part of the complex number which is converted into Polar co-ordinates, $\mathrm{R}$ and $\theta$ using following equations.

$$
\begin{gathered}
\mathrm{R}(\mathrm{k})=\sqrt{\mathrm{v}_{1}(\mathrm{k})^{2}+\mathrm{v}_{2}(\mathrm{k})^{2}} \\
\theta(\mathrm{k})=\tan ^{-1} \frac{\mathrm{v}_{2}(\mathrm{k})}{\mathrm{v}_{1}(\mathrm{k})}
\end{gathered}
$$

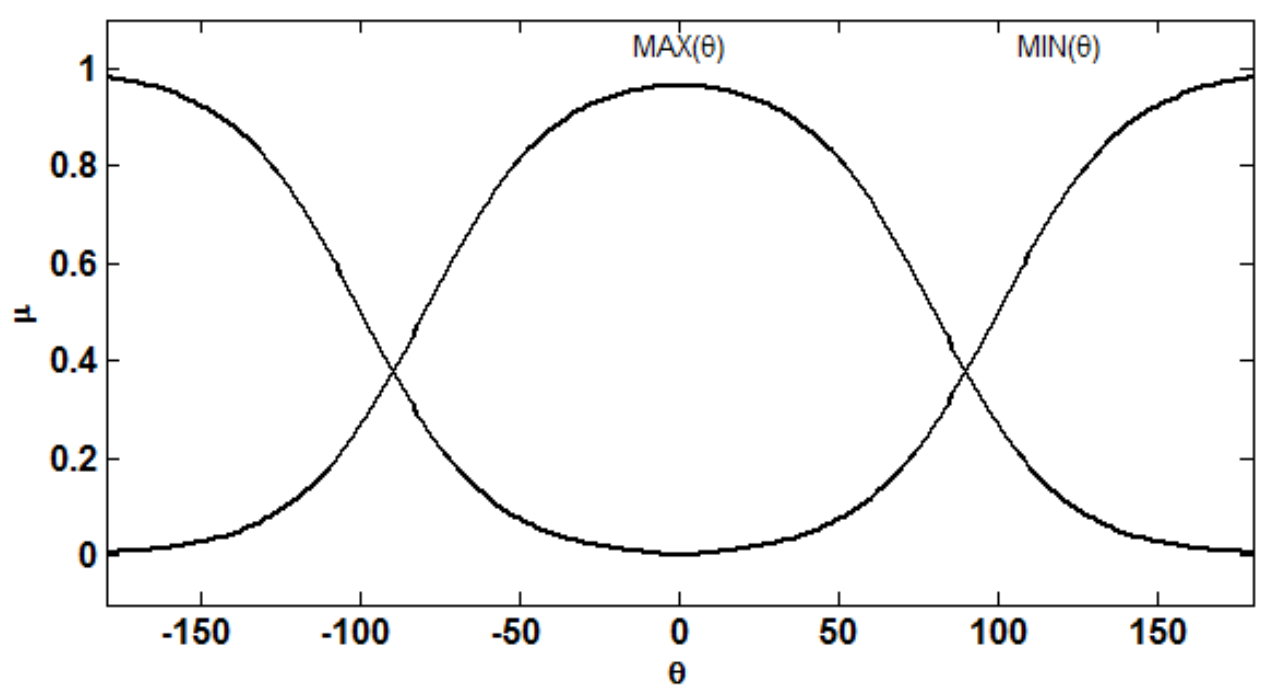

Fig. 4. Input Membership Function

In PFLC angle $\theta$ is given as input. Two linguistic variables are formed $\operatorname{MAX}(\theta)$ and $\operatorname{MIN}(\theta)$ as shown in Fig. 4 , where $\operatorname{MAX}(\theta)+\operatorname{Min}(\theta)=1$. Range of $\theta$ varies from $-180^{\circ}$ to $+180^{\circ}$. The membership function value $\mu$ is determined by following equation.

$$
\boldsymbol{\mu}=\mathbf{x} \tan \boldsymbol{\theta}(11)
$$

Where $\mathrm{x}$ is the fuzzy element. At sampling instant $\mathrm{k}, \theta$ is given to the input Differential Sigmoidal membership function, corresponding value $\mu$ is mapped using equation number (11) into output Triangular membership function. 
Output Membership function $\mathrm{v}_{\mathrm{o}}$ is defined in two linguistic variables $\mathrm{P}$ (Positive) and $\mathrm{N}$ (Negative). When $\theta$ is $-180^{\circ}$ or $+180^{\circ}$, the membership function value of $\operatorname{MAX}(\theta)$ is minimum. Thus output $\mathrm{v}_{\mathrm{o}}$ should be ' $\mathrm{P}$ '. When $\theta$ is $-90^{\circ}$ or $+90^{\circ}$, both input membership function has same value so output $\mathrm{v}_{\mathrm{o}}$ should not be changed.

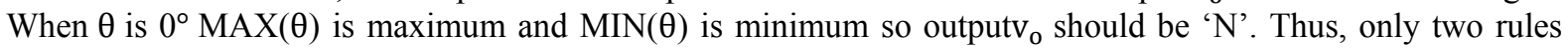
are defined as follows.

(i) If $\theta$ is $\operatorname{MAX}(\theta)$ then output $\mathrm{v}_{\mathrm{o}}$ is $\mathrm{P}$

(ii) If $\theta$ is $\operatorname{MIN}(\theta)$ then output $\mathrm{v}_{\mathrm{o}}$ is $\mathrm{N}$

Centroid method is used to convert from fuzzy set to a crisp number. This crisp number which is output of the PFLC, is denoted as $U_{P F}$ as shown in Fig. 5. $U_{P F}$ is multiplied by $R$ and final output $p_{\text {loss }}$ is developed, which is used to generate reference current for the proper functioning of SAPF. Thus, magnitude of the output depends on $\mathrm{R}$ and decision is taken by $\theta$.

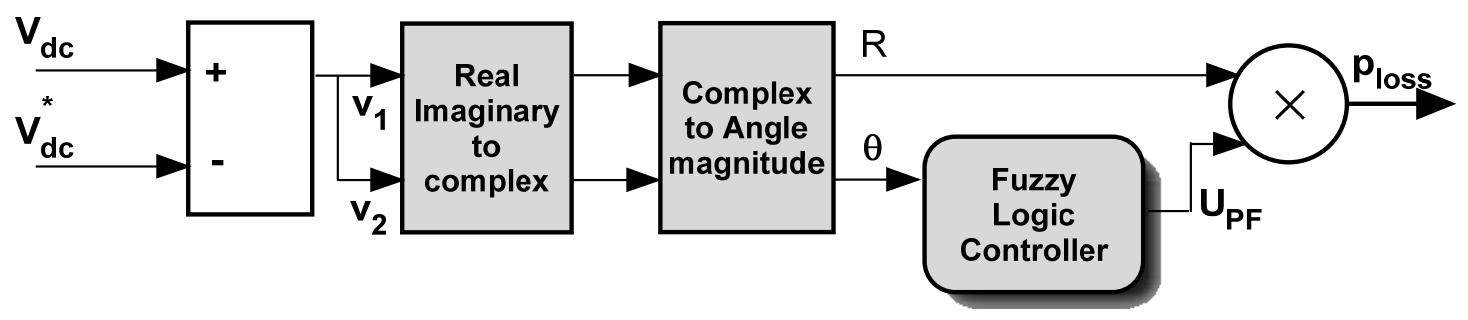

Fig. 5. Block diagram of Polar Fuzzy logic controller

\section{IV.Modelling of Shunt Active Power Filter}

The purpose of the VSI is to provide three phase sinusoidal voltage with required amplitude, frequency and phase difference. It has inductors on the supply side and dc-link capacitor on the other side as shown in Fig. 1. Dynamic model of PWM based VSI can be outlined by equation number (12) to (20).

$$
\begin{aligned}
& \left\{\begin{array}{l}
v_{a}=L_{f} \frac{d i_{f a}}{d t}+R_{f} i_{f a}+v_{s a} \\
v_{b}=L_{f} \frac{d i_{f b}}{d t}+R_{f} i_{f b}+v_{s b} \\
v_{c}=L_{f} \frac{d i_{f c}}{d t}+R_{f} i_{f c}+v_{s c}
\end{array}\right. \\
& \left\{\begin{array}{l}
i_{f a}=i_{s a}+C_{f} \frac{d\left(v_{s a}-v_{s b}\right)}{d t}+C_{f} \frac{d\left(v_{s a}-v_{s c}\right)}{d t} \\
i_{f b}=i_{s b}+C_{f} \frac{d\left(v_{s b}-v_{s a}\right)}{d t}+C_{f} \frac{d\left(v_{s b}-v_{s c}\right)}{d t} \\
i_{f c}=i_{s c}+C_{f} \frac{d\left(v_{s c}-v_{s b}\right)}{d t}+C_{f} \frac{d\left(v_{s c}-v_{s b}\right)}{d t} \\
L_{s} \frac{d i_{s a}}{d t}+R_{s} i_{s a}=v_{s a}-e_{a} \\
L_{s} \frac{d i_{s b}}{d t}+R_{s} i_{s b}=v_{s b}-e_{b} \\
L_{s} \frac{d i_{s c}}{d t}+R_{s} i_{s c}=v_{s c}-e_{c}
\end{array}\right.
\end{aligned}
$$

\section{Estimation OF System PARAMETERS}

The SAPF consists of six IGBTs and capacitor on the DC side. The SAPF of power rating 45 KVA is designed for phase voltage of $230 \mathrm{~V}$ and $50 \mathrm{~Hz}$ supply. Three phase diode rectifier is connected with three-phase supply which has non-linear characteristics. This rectifier is supplying 200A constant current to the load connected to it. Following equation is used to estimate capacitor voltage.

$$
\mathrm{C}_{\mathrm{DC}}=\mathrm{I}_{\mathrm{d}} /\left(2 \omega \mathrm{V}_{\text {DCripple }}\right) \text {, }
$$

where $I_{d}$ is the supply current of active filter, $V_{\text {DCripple }}$ is maximum value of DC link voltage of ripples, and $\boldsymbol{\omega}=\mathbf{2 \pi f}$, where $\mathrm{f}$ is the supply frequency. Filter impedance selection can be done using

$$
\mathrm{L}_{\mathrm{f}}=\sqrt{3} \mathrm{mV}_{\mathrm{DC}} /\left(12 \mathrm{af}_{\mathrm{s}} \mathrm{I}_{\text {ripple }}\right) \text {, }
$$

where $\mathrm{I}_{\text {ripple }}$ is current ripple, $\mathrm{m}$ is modulation index, $\mathrm{a}$ is overloading factor and $\mathrm{f}_{\mathrm{s}}$ is switching frequency. The calculated system parameters for the simulation purpose are given in Table 1. 
TABLE I. System Parameters

\begin{tabular}{|l|l|}
\hline System Parameter & Value \\
\hline Source Voltage $\left(\mathrm{V}_{\mathrm{s}}\right)$ & $400 \mathrm{~V}$ \\
\hline System Frequency $(\mathrm{f})$ & $50 \mathrm{~Hz}$ \\
\hline Switching Frequency $\left(\mathrm{f}_{\mathrm{s}}\right)$ & $10 \mathrm{KHz}$ \\
\hline Source Impedance $\left(\mathrm{R}_{\mathrm{s}} \mathrm{L}_{\mathrm{s}}\right)$ & $0.04 \Omega, 1.2 \mathrm{mH}$ \\
\hline Filter Impedance $\left(\mathrm{R}_{\mathrm{f}} \mathrm{L}_{\mathrm{f}}\right)$ & $2 \Omega, 0.75 \mathrm{mH}$ \\
\hline Load Impedance $\left(\mathrm{R}_{\mathrm{L}}, \mathrm{L}_{\mathrm{L}}\right)$ & $2.7 \Omega, 10 \mathrm{mH}$ \\
\hline Reference dc link Voltage $\left(\mathrm{V}_{\mathrm{dc}}^{*}\right)$ & $700 \mathrm{~V}$ \\
\hline
\end{tabular}

VI.SIMULATION RESULTS

Three-phase SAPF model is developed in Matlab/Simulink block and dc-link voltage has been controlled using PI controller and PFLC. The three-phase supply voltage is taken sinusoidal and balanced. The power system and SAPF are three-phase but the results are captured to show waveform for single phase because balanced non-linear load is taken for simulation. In the first case, the Total Harmonic Distortion (THD) factor is $20.65 \%$, when the highly non- linear load is connected with the supply. Source current waveform deteriorates as shown in Fig. 7. This waveform shows the effect of non-linear load without SAPF in the system. The simulation result is shown in Fig. 9 when PFLC is connected to control SAPF in the system, it is depicted that the sinusoidal waveform received in two cycles. The Fig. 8 shows source current wave shapes when SAPF is connected and controlled with conventional PI.

In case of PI controller, the reduction in the level of odd harmonic factor(THD) is observed $4.7 \%$ and with PFLC the achieved the reduction to $4.41 \%$ of THD. The simulation results are compared by taking different values of capacitance $(\mathrm{C})$ and inductance $(\mathrm{L})$. By varying the parameters, the value of THD is varies $\pm 0.05 \%$.

The value of $\mathrm{kp}$ and ki is taken 0.2 and 9.25 respectively to control the dc voltage with PI controller. DC link voltage settlement graph is shown in Fig. 6. It is clearly seen from the graph that DC link voltage achieves its steady state value earlier in case of PFLC.

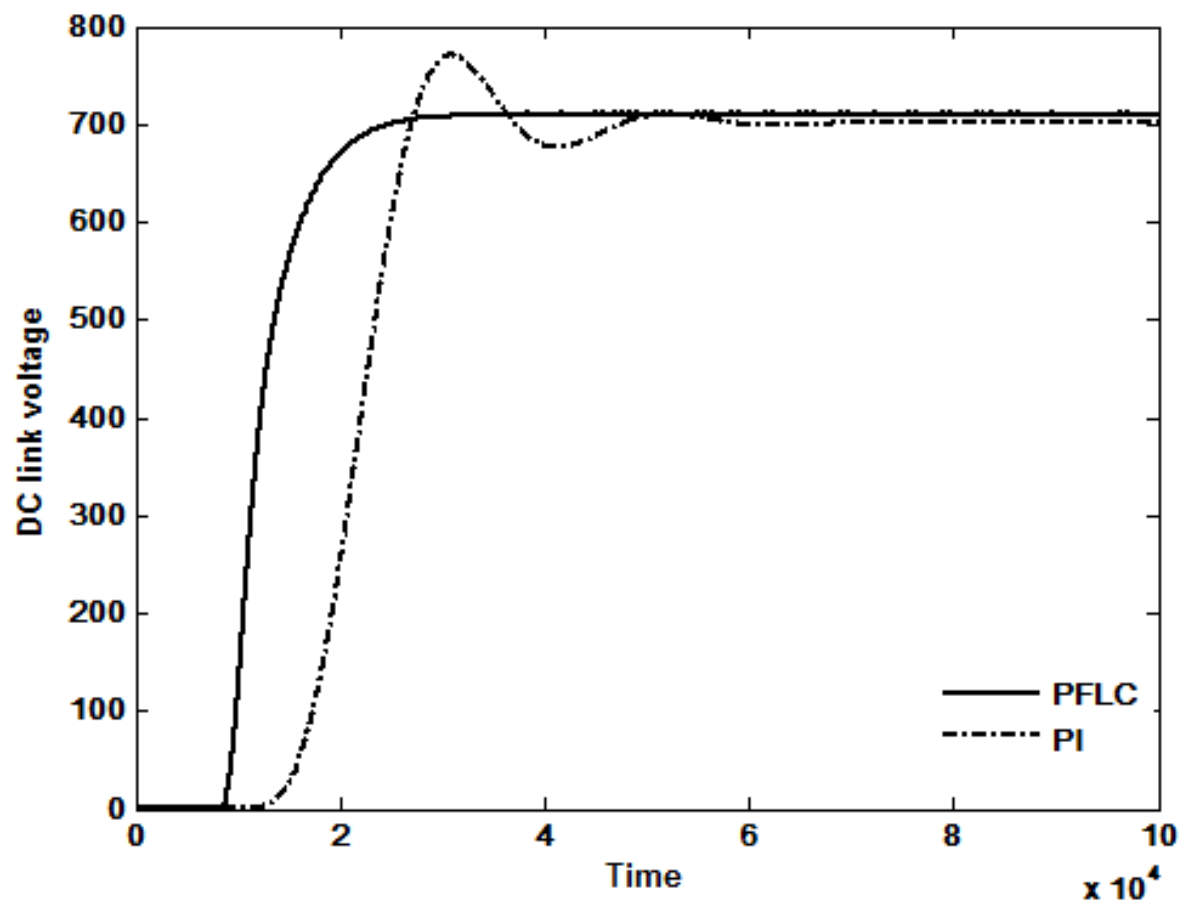

Fig. 6. DC link voltage with PI controller and PFLC 


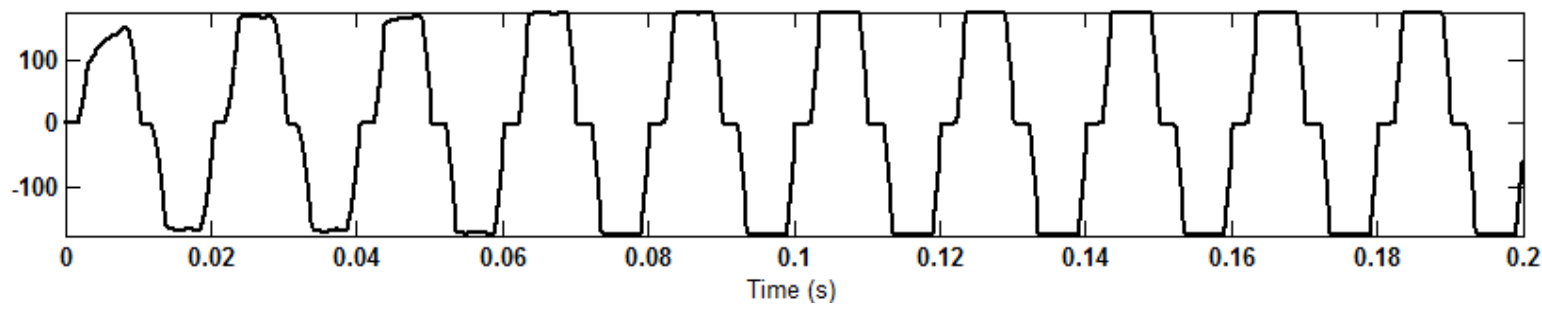

Fig. 7. Source Current Waveshape when SAPF not connected

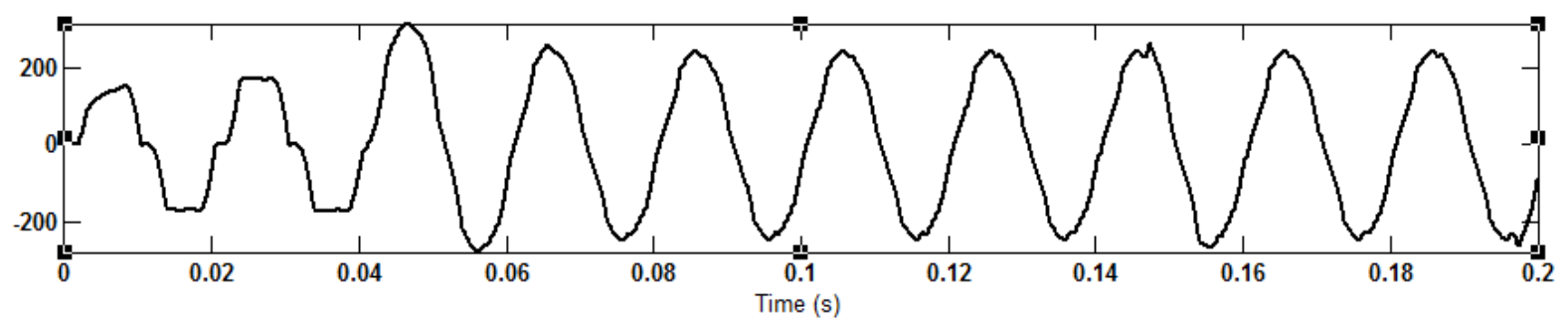

Fig. 8. Source Current Waveshape with PI

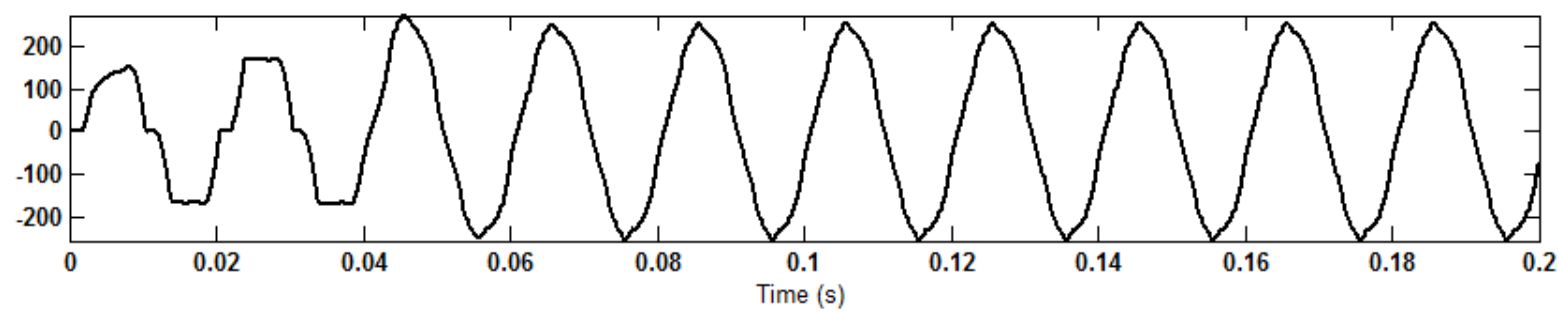

Fig. 9. Source Current Waveshape with PFLC

\section{CONCLUSION}

For more stable system Polar based three phase active filter is implemented. System stability depends on quick response of the controller when load disturbance occurs. Performance of the SAPF depends on entanglement and estimated operational time of the controller. In this paper, PFLC is designed with two membership functions to save the computational time. PFLC is better than traditional FLC because it has less number of fuzzy rules as compared to 49 fuzzy rules used in FLC.

The results of PFLC is compared with conventional PI controller. Simulation results shows that PFLC settles dc link voltage smoothly as compared to PI controller and reduces harmonics effectively and satisfies the permissible limit of 5\% according to IEEE-519 standard.

In addition to that, the PFLC has been verified with different set of values of system parameters like filter inductance and filter capacitance. It is observed that the PFLC is enough robust to handle the various disturbances. Hence, polar fuzzy controller is good alternate to the conventional PI controller for reducing current harmonics.

\section{REFERENCES}

[1] Akagi H, Atoh S, Nabae A. "Compensation Characteristics of active power filter using multi-series voltage-source PWM converters,'Electrical Engineering Japan. 106(5): 28-36, 1986.

[2] Singh B, Chandra A, Al-Haddad K. Power Quality: Problems and Mitigation Techniques. Chichester, West Sussex, England: John Wiley \& Sons Ltd, 2015.

[3] Chatterjee K, Fernandes BG, Dubey GK. "An instantaneous reactive volt-ampere compensator and harmonic suppressor system.”IEEE Transactions on Power Electronics. 14(2): 381-392, Mar 1999.

[4] Consalva J, Msigwa Kundy BJ, Mwinyiwiwa BMM. "Control Algorithm for Shunt Active Power Filter using Synchronous Reference Frame Theory,” World Academy of Science, Engineering and Technology.3(10): 1828-1834, 2009.

[5] Singh B, Chandra A, Al-Haddad K. "Computer-aided modeling and simulation of active power filters,"Electrical Machines and Power System. 27: 1227-1241,1999.

[6] Jain SK, Agrawal P, Gupta HO. "Fuzzy Logic Controlled Shunt Active Power Filter for Power Quality Improvement," IEE Proceedings Electric Power Applications.149(5): 317-328, 2002.

[7] Mikkili S, Panda AK. Power Quality Issues Current Harmonics. CRC Press. 2016.

[8] Kumar P, Mahajan A, "Soft Computing Techniques for the Control of an Active Power Filter,"IEEE Transactions on Power Delivery; 24(1): $452-461,2009$.

[9] Xia L, Taihang D, Shengxue T. "Fuzzy Logic Variable Hysteresis Band Current Control Technique for Three Phase Shunt Active Power Filter.”International Conference on Control, Automation and Systems Engineering, 2011.

[10] Gupta N, Singh SP, Dubey SP. "Fuzzy logic controlled shunt active power filter for reactive power compensation and harmonic elimination,"2nd International Conference on Computer and Communication Technology, 2011. 
[11] Mikkili S, Panda AK. "SHAF for mitigation of Current harmonics with p-q and Id-Iq control strategies using both PI and Fuzzy Controllers,"International Conference on Sustainable Energy and Intelligent Systems, 2011.

[12] Hamadi A, Al-Haddad K, Lagace PJ, Chandra A. "Indirect current control techniques of three phase APF using fuzzy logic and proportional integral controller: comparative analysis,"International Conference on Harmonics and Quality of Power, 2004.

[13] Karuppanan P, Mahapatra K. "PLL with PI, PID and fuzzy logic controllers based shunt active power line conditioners,"International Conference on Power Electronics, Drives and Energy Systems. IIT-Delhi, India;21-23: December 2010.

[14] Zelloumaa L, Rabhib B, Saadc S, Benaissad A,Benkhorise MF. "Fuzzy Logic Controller of Five Levels Active Power Filter," Energy Procedia 2015; 74:1015-1025.

[15] Panda AK, Patel R. "Adaptive hysteresis and fuzzy logic controlled-based shunt active power filter resistant to shoot-through phenomenon,'IET Power Electronics. 8(10),2015.

[16] Lazi JM, Ibrahim Z, Sulaiman M, Patakor FA, Isa SNM. "Fuzzy Logic Speed Controller with Reduced Rule Base for Dual PMSM Drives,”World Academy of Science, Engineering and Technology,5(5): 623-628, 2011.

[17] Hadipriono F, Sun K. “Angular Fuzzy Set Models for Linguistic values, Civil Engineering Systems," 7(3): 148-156,1990.

[18] IEEE Recommended Practices and Requirements for Harmonic Control in Electrical Power Systems:1993, IEEE Std. 519-1992.

[19] Akagi H, Watanabe EH, Aredes M. Instantaneous power theory and applications to power system, IEEE Press. A john wiley \& sons Publication, 2007.

[20] Chaturvedi DK. Soft Computing Techniques and its Applications in Electrical Engineering, Springer; 2008.

\section{AUTHOR PROFILE}

Harsha Vanjani is pursuing research in the field of Power Electronics from Ansal University, Gurgaon. She is a dedicated academician having over 10 years of experience. Ms. Vanjani completed herB. Techin the field of Electrical Engineering in the year 2004 from Saurashtra University and M. Tech in power apparatus \& systems in the year 2006 from Nirma University, Ahmedabad.

Dr. Meha Sharma has done Ph.D. from Banasthali University, Rajasthan. She is working as Assistant professor in Ansal University She has published many papers in renowned journals at national and International level. She is expert in Microprocessor, Microcontroller, Matlab, Digital Signal Prosessing at Undergraduate level

Dr. U.K Choudhury has done Ph.D. from Jamia Millia Islamia (Central University), M.Tech. from Delhi Technological University and B.E from University College of Engineering, Burla, Orissa.He is working as Associate Professor in Delhi Technology Campus. With an experience of more than 17 years, Dr. Choudhury has worked in Industry, Govt. Institutes and reputed Engineering colleges in NCR region. 